\title{
CASTING OF Fe-Cr-TiC COMPOSITES USING IN-SITU METHOD
}

\author{
Srinivasa $K^{1}$, K I Parashivamurthy ${ }^{2}$, Prajwal A $S^{3}$, Rakshith $\mathbf{N}^{4}$ \\ ${ }^{1}$ Associate Professor, Department of Mechanical Engineering, ATME College of Engineering, Mysore, India \\ ${ }^{2}$ Professor, Department of Mechanical Engineering, Govt. College of Engineering, Chamarajanagara, India \\ ${ }^{3}$ Assistant Manager, Dynamatic-Oldland Aerospace, Bangalore, India \\ ${ }^{4}$ Assistant Professor, Department of Mechanical Engineering, ATME College of Engineering, Mysore, India
}

\begin{abstract}
Titanium carbide is varying from 3.5 to $14 \%$ volume fraction was reinforced by the direct reaction of pure titanium in molten Fe$\mathrm{Cr}$ alloy. To improve precipitation and distribution of titanium carbide in Fe-Cr matrix, a simple casting technique has been developed successfully. A protective layer on the molten metal is used to avoid oxidation of titanium during melting and casting. The kinetic and thermodynamic studies support the precipitation of TiC in molten $\mathrm{Fe}$-Cr alloy at $1600^{\circ} \mathrm{C}$ reaction temperature. Based on the amount of titanium and chromium present in $\mathrm{Fe}$-Cr molten alloy, the size and shape of the chromium and titanium carbide particles depends.
\end{abstract}

Keywords: TiC, Precipitation, Metal Matrix, Casting, Morphology.

\section{INTRODUCTION}

Ferrous based metal matrix composites [MMC's] have attracted the considerable attention of researches in the field of material science in recent years as they posse's potential improved properties over commercial metals and alloys. In recent years, particle reinforced iron matrix composites have been a core of attention within the range of new materials [1-2]. Based on earlier investigations, incorporation of ceramic particles i.e. $\mathrm{Al}_{2} \mathrm{O}_{3}, \mathrm{SiC}, \mathrm{TiB}_{2}, \mathrm{WC}$ and $\mathrm{TiC}$ in an iron metal matrix give great improvement on the mechanical and wear properties of iron and its alloys. Among these ceramic particles, TiC had drawn much attention as reinforcements in iron matrix due to its high hardness, wear resistance, high chemical stability, high thermal and shock resistance.[3] Iron based composites with reinforcement of $\mathrm{TiC}$ particles have received interest in these classes of materials. [4-5] although, most of the work on iron based composites are centred on low and medium carbon steel to improve upon their wear resistance, strength and stiffness of the composites. TiC particles with high hardness are widely used as the reinforcing phase for iron matrix due to good wettability with liquid iron [6]. The TiC phase strongly influences the mechanical, wear and corrosion properties by bonding with matrix of iron [7]. Bandyopadyay and Das synthesis the $\mathrm{TiC}$ reinforced ferrous based composites for wear resistance application [5]. The ferrous matrix prepared is having high wear resistance but, high brittleness. Prarahivamurthy et al [8] also developed TiC reinforced composites by In-Situ technique and observed in improved wear and erosion properties along with reduced tensile properties. But, in many industrial applications, ferrous matrix composites essential to provide combination of wear properties with toughness gives high service life of the components. The various alloying elements like $\mathrm{Ni}, \mathrm{Cr}, \mathrm{Mn}$ etc. enhances the properties in the matrix of iron. The alloying elements like chromium, up to $12 \%$ increases toughness and wear resistance of the steel [10].

In-situ casting method for synthesizing the $\mathrm{TiC}$ crystals in the molten iron is observed by reacting titanium along with carbon in molten iron. TiC precipitation is occurring is based on the thermodynamically first order of kinetic reaction [12-13]. The synthesizing the $\mathrm{TiC}$ particles in $\mathrm{Fe}-\mathrm{Cr}$ molten alloy $\mathrm{Cr}$ promote the formation of $\mathrm{TiC}$ along with toughened matrix austenitic face. Thus, the present work focuses on the casting $\mathrm{Fe}-\mathrm{Cr}$-TiC composites using In-Situ method and assigning morphology of TiC precipitation. 


\section{EXPERIMENTAL PROCEDURE}

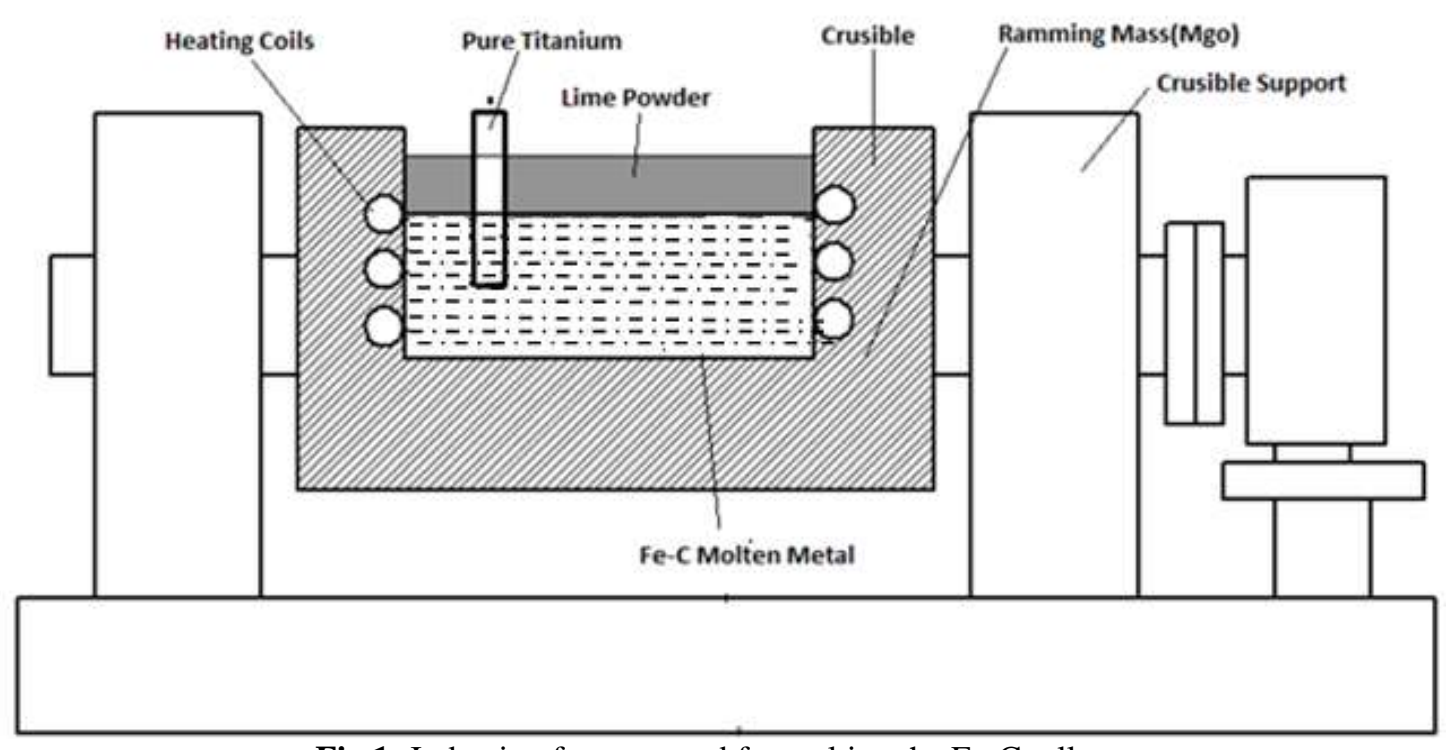

Fig 1: Induction furnace used for melting the $\mathrm{Fe}-\mathrm{Cr}$ alloys

Fig.1 shows that an induction furnace used for melting the alloys. A container of high refractory crucible was used to fabricate Fe-Cr-TiC composites. The outer layer of the crucible was covered with a thin asbestos sheet and it was placed at the centre of the furnace cavity. Also, fine powder of Mgo based ramming mass was filled in gap between the coil surface and crucible. In order to remove the surface moisture prior to filling up the ramming mass was preheated in an air oven and the powder was rammed because no air pockets remained around the crucible. After the furnace preparation was completed, the base alloy materials were charged. The power to the furnace was switched on and the power was increased in steps of $1 \mathrm{KW}$ for every 5 minutes till it reached a value of $10 \mathrm{KW}$. A series of Fe-Cr-TiC metal matrix composites were produced by reacting pure titanium in molten $\mathrm{Fe}-\mathrm{Cr}$ alloy. Lime powder of thickness $5 \mathrm{~cm}$ is covered over the molten metal to avoid titanium reaction with oxygen.

For $\mathrm{TiC}$ formation, the total carbon required to be added was calculated by using atomic weight ratio. Four castings were prepared by varying titanium carbide content in the range of $3.5 \%$ to $14 \%$. Through the lime powder, a calculated weight of titanium bar was plunged in to the liquid $\mathrm{Fe}-\mathrm{Cr}$ melt to form titanium carbide. After fifteen minutes, of reaction the composite liquid metal was poured in to sand moulds. Four in-situ $\mathrm{Fe}-\mathrm{Cr}-\mathrm{TiC}$ composites were produced by sand casting.

\section{RESULTS}

Chemical analytical data of the $\mathrm{Fe}-\mathrm{Cr}-\mathrm{TiC}$ composites are shown in table 1 . The castings are designated 1,2,3,4 and 5 for reference based on the volume fraction of $\mathrm{TiC}$ in each of them. The volume fraction was measured by optical microscopic technique.
Table 1: Chemical analysis of Fe-Cr-TiC composites in (wt

\begin{tabular}{|c|c|c|c|c|c|c|}
\hline Sample no & $\mathbf{C}$ & $\mathbf{M n}$ & $\mathbf{N i}$ & $\mathbf{C r}$ & $\mathbf{T i}$ & $\mathbf{F e}$ \\
\hline 1 & 0.83 & 0.66 & 0.11 & 13.58 & 0.036 & Balance \\
\hline 2 & 0.85 & 0.52 & 0.94 & 12.58 & 3.99 & Balance \\
\hline 3 & 1.37 & 0.56 & 0.00 & 12.48 & 7.56 & Balance \\
\hline 4 & 1.63 & 0.73 & 0.00 & 12.36 & 10.36 & Balance \\
\hline 5 & 2.14 & 0.36 & 0.00 & 12.24 & 14.51 & Balance \\
\hline
\end{tabular}

Fig. 2 and 3 shows that the typical optical microstructures of Fe-Cr-TiC composites at two magnifications of $100 \mathrm{X}$ and $400 \mathrm{X}$ for the sample 3 and 5 . The structure shows the distribution of the carbide in the matrix with well defined grain boundary. With increasing carbon and titanium contents, the size of the carbide increases.

Energy-dispersive X-ray spectroscopy [EDX] is an analytical technique used for the elemental analysis or chemical characterisation. Fig. 4 shows energy dispersive Xray analysis for sample 3 . The energy dispersive profile data of the $\mathrm{Fe}-\mathrm{Cr}-\mathrm{TiC}$ shows that 13 percent chromium is dissolved in the matrix of steel for sample 3 which is comparable in with the chemical analysis data (table 1).

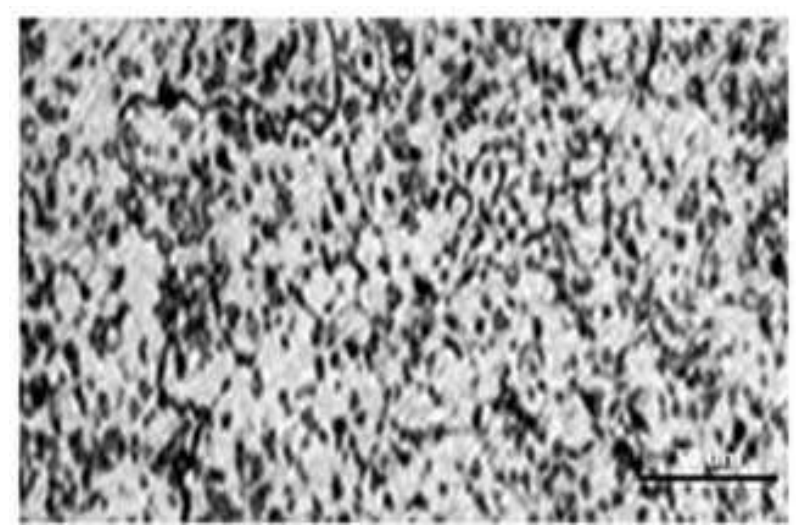

Fig 2: Optical microstructure of sample 3 with (a) lower Magnification 


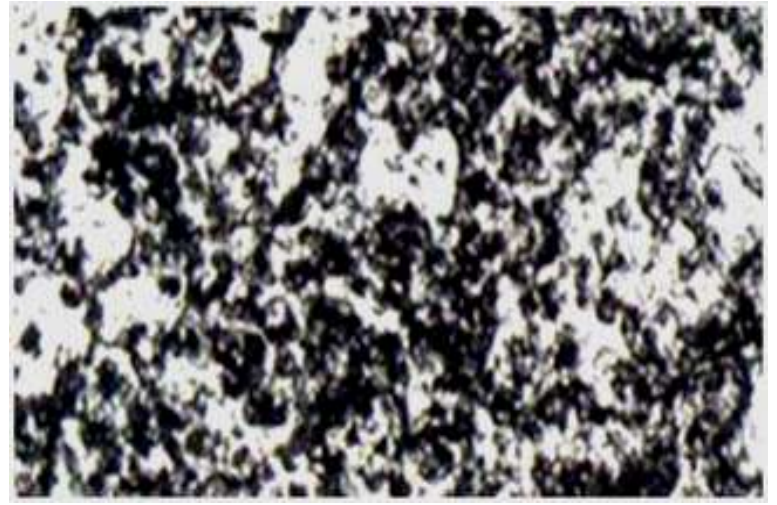

Fig 2: Optical microstructure of sample 3 with (b) higher magnification

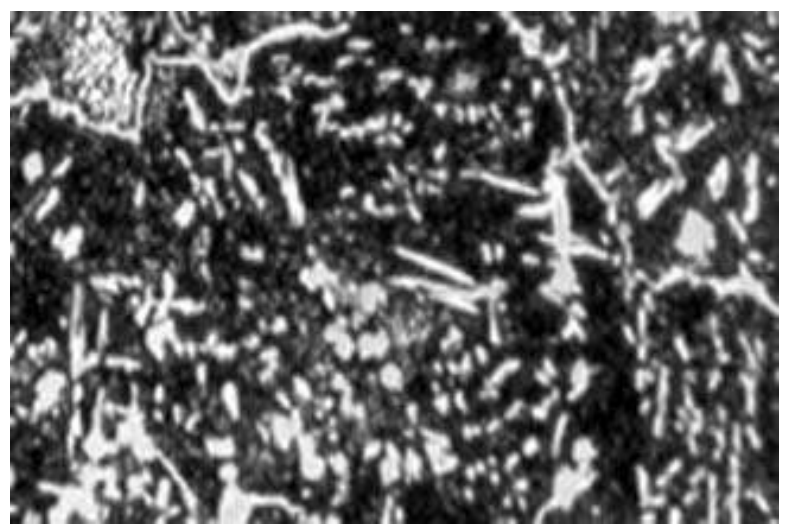

Fig 3: Optical microstructure of sample 5 with (a) Lower magnification

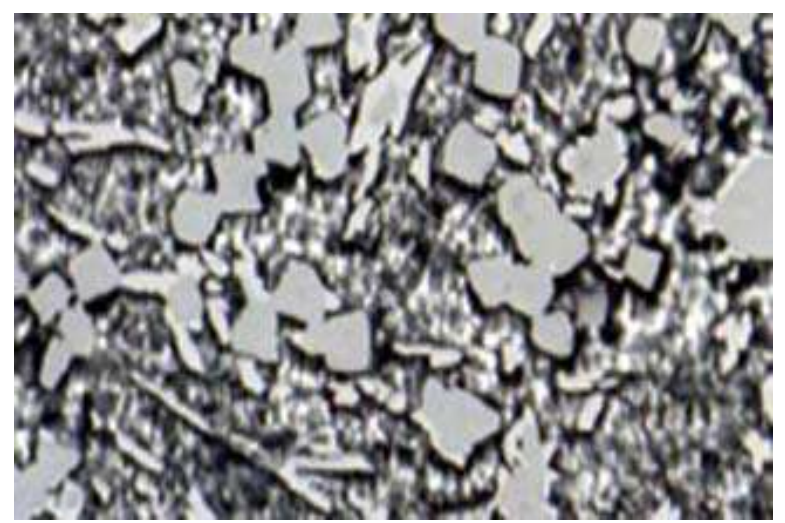

Fig 3: Optical microstructure of sample 5 with (b) higher magnification

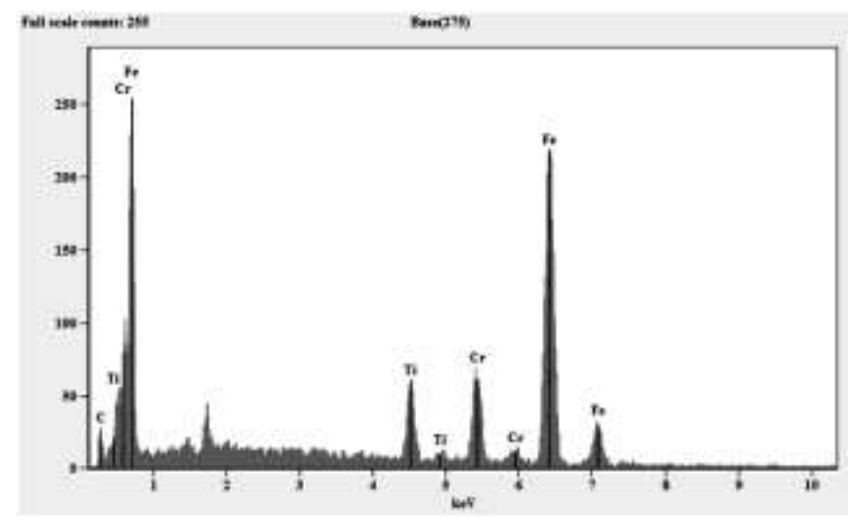

Fig 4: shows X-ray diffractogram of sample 3

\section{DISCUSSION}

In present investigation $\mathrm{TiC}$ reinforced $\mathrm{Fe}-\mathrm{Cr}$ matrix alloy composite is prepared by In-situ method. During the casting titanium directly reacts with available carbon and converted in $\mathrm{TiC}$ at $1600 \mathrm{C}^{\circ}$ [10]. The precipitation of $\mathrm{TiC}$ in molten $\mathrm{Fe}-\mathrm{Cr}$ alloy can be explained based on thermodynamic and kinetics of Fe-Cr-TiC studies. During the casting, the following reactions may be occurring as follows.

$$
\begin{gathered}
{[\mathrm{Ti}]+[\mathrm{C}]=\operatorname{TiC}(s)} \\
{[\mathrm{Cr}]+[\mathrm{C}]=\operatorname{CrC}(\mathrm{s})} \\
{[\mathrm{C}]+3[\mathrm{Fe}]=\operatorname{Fe} 3 C(s)} \\
{[\mathrm{Ti}]+[\mathrm{Fe}]=\operatorname{FeTi}(\mathrm{s})}
\end{gathered}
$$

The precipitation of $\mathrm{TiC}$ in the molten of Fe-Cr-Ti-C molten alloy is at $1600^{\circ} \mathrm{C}$ and continuously grows as temperature decreases [8]. The TiC crystal is more stable the $\mathrm{CrC}, \mathrm{Fe}_{3} \mathrm{C}$ and $\mathrm{FeTi}$ and it precipitates at first up to the temperature $1000 \mathrm{C}^{\circ}[10]$. Between the 1000 and $1600 \mathrm{C}^{\circ}, 4 \%$ titanium reacts with $1 \%$ carbon and carbon concentration is continuously decreases till reaches $0.84 \%$ in residue liquid. In the beginning, titanium available in the $\mathrm{Fe}-\mathrm{Cr}-\mathrm{C}$ molten alloy reacts with available carbon and converted in to $\mathrm{TiC}$ and it reduces the carbon concentration in the molten liquid. In Fe-Cr-Ti-C molten, the amount of carbon solubility in austenite decreases as the chromium added to iron, the temperature of the eutectoid reaction is raised and the carbon content of the eutectoid is diminished. Chromium reduces the rate of cooling, when temperature changes this effect may results in appearing equiaxed $\mathrm{TiC}$ crystals in alloy of $\mathrm{Fe}-\mathrm{Cr}-\mathrm{C}$ system. This can be clearly visible in the optical microscope at lower and higher magnification. Below the $1000 \mathrm{C}^{\mathrm{o}}$, the $\mathrm{Fe}-\mathrm{Cr}$ starts to solidify by forming austenite with dissolved carbon content $0.8 \%$. The temperature further decreases, i.e. below $723 \mathrm{C}^{\circ}$, the austenite further decompose and converted in to ferrite and pearlite. Finally, the structure consists of TiC precipitation along with ferrite at room temperature. This structure may helps in the $\mathrm{Fe}-\mathrm{Cr}-\mathrm{TiC}$ composites wear and erosion along with toughness which is required most of the industrial components works at wear and erosive environments.

According to Gibbs free energy explains in details about formation of $\mathrm{TiC}$ in the molten $\mathrm{Fe}-\mathrm{Ti}-\mathrm{C}$. If the temperature vary the standard forming Gibbs free energy of the possible products like $\mathrm{TiC}, \mathrm{Fe}_{3} \mathrm{C}$, and $\mathrm{Fe}_{2} \mathrm{Ti}$ varies. Among these products $\mathrm{TiC}$ is lowest, compared to that of $\mathrm{Fe}_{3} \mathrm{C}$ and $\mathrm{Fe}_{2} \mathrm{Ti}$, Therefore the formation of $\mathrm{TiC}$ phase thus favoured over of $\mathrm{Fe}_{3} \mathrm{C}$, and $\mathrm{Fe}_{2} \mathrm{Ti}$ meaning that $\mathrm{TiC}$ phase would appear in the composites [15]

Kinetic theory of $\mathbf{T i C}$ precipitation $\mathrm{TiC}$, precipitation process considered thermodynamically first order in the Ehrenest classification [9]. The formation of each carbide particle is requires nucleation in the traditional way and 
subsequent growth. According to the thermodynamic and kinetic studies titanium is a reacting constituent react with carbon in molten steel and dispersed as solid TiC particles. According to thermodynamic data, the formation of Fe-TiC system at $\mathrm{T}^{\circ} \mathrm{C}[\mathbf{8}]$ is as shown in equation 1 .

The procedure used for the formation of carbide particle reinforcements involves plunging of a pure titanium rod in molten $\mathrm{Fe}-\mathrm{C}$ alloy and reacts with carbon at the processing temperature of $1600 \pm 50^{\circ} \mathrm{C}$. The precipitation of $\mathrm{TiC}$ in molten $\mathrm{Fe}-\mathrm{C}$ alloy can be explained on the basis of thermodynamic and kinetics studies. According to thermodynamic data, the formation of Fe-Tic system at $1600^{\circ} \mathrm{C}$ occurred in conformity with equation

$\mathrm{Ti}(l)+C(l) \stackrel{\text { Molten Fe }}{\longrightarrow} \mathrm{Fe}-\mathrm{TiC}(s)$

At equilibrium, the standard free energy changes will be [14]

$$
\Delta G^{o}=-R T \ln \left(\frac{1}{a_{T i} a_{C}}\right)
$$

Where $\mathrm{T}$ is the temperature of the molten alloy, $\mathrm{a}_{\mathrm{Ti}}$ and $\mathrm{a}_{\mathrm{c}}$ are the activities of titanium and carbon, respectively, and $\mathrm{R}$ is the universal gas constant.

$a_{T i} a_{C}>e^{\Delta G^{0} / R T}$

At higher temperature, the exponential term in equation (3) will be less and the reaction will be more. TiC is thermodynamically the compound favoured to precipitate at the reaction temperature, $1600^{\circ} \mathrm{C}$. The activity of iron in the melt is less when compared to titanium, Hence. Kinetically, it is more favourable for the formation of Tic in the $\mathrm{Fe}-\mathrm{Cr}-\mathrm{C}$ molten alloy at $1600^{\circ} \mathrm{C}$.

The phase diagram (Figure 5) describes the composites consisting of reinforcements of $\mathrm{TiC}$ in the matrix of ironChromium. In the reaction, initially $\mathrm{TiC}$ nucleates because titanium has an affinity for carbon when compared to iron and chromium, and the distance A-TiC gives the associated free energy, when $\mathrm{TiC}$ precipitates first. The residual driving free energy for the formation of iron carbide and chromium carbide decreases, and it is represented by $\mathrm{B}-\mathrm{CrC}$ and $\mathrm{C}$ $\mathrm{Fe}_{3} \mathrm{C}$. As the driving free energy is reduced by the nucleation of $\mathrm{TiC}$, it may be presumed that the $\mathrm{Fe}_{3} \mathrm{C}$ and $\mathrm{CrC}$ will not nucleate during the composite formation because of kinetic difficulties. As a result, iron carbide and chromium carbide will not appear in the composite casting. Therefore, TiC alone will nucleate and stabilize in the matrix. Furthermore, X-ray diffraction analysis confirms the non-precipitation of iron carbide and chromium carbide in the matrix of iron chromium [16].

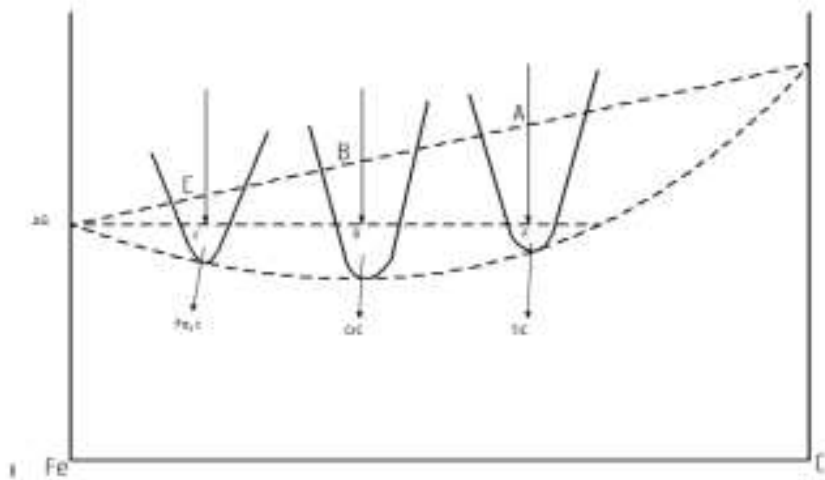

Fig 5: Schematic Free Energy Diagram for Hypothetical Composites

\section{CONCLUSION}

Titanium carbide varying volume fractions reinforced in molten $\mathrm{Fe}-\mathrm{Cr}$ alloy have been developed by in-situ technique. Four samples of $\mathrm{Fe}-\mathrm{Cr}-\mathrm{TiC}$ composites were produced, the samples are investigated of their precipitation behaviour and micro structural characteristics were carried out. Based on the experimental results the following conclusions are arrived.

1. With varying volume fractions of titanium carbide reinforced in molten $\mathrm{Fe}-\mathrm{Cr}$ alloy can be produced by insitu technique.

2. Under protective cover of lime, the addition of pure titanium holds good promise for producing $\mathrm{Fe}-\mathrm{Cr}-\mathrm{TiC}$ composites.

3. The titanium and carbon content in the $\mathrm{Fe}-\mathrm{Cr}$ alloy are mainly dependent of $\mathrm{TiC}$ size, shape and distribution. The larger TiC size and volume fraction in composites is due to high titanium and carbon content.

4. The analysis of X-ray energy dispersive analysis confirmed that the $\mathrm{TiC}$ precipitated in all four samples. Titanium carbide precipitates at higher temperature than chromium carbide and iron carbide of the higher affinity of titanium for carbon.

\section{REFERENCES}

[1] J. Lee, K, Eah, J.C.Oh and S.Lee, microstructure and hardness improvement of $\mathrm{TiC} /$ stainless steel surface composites fabricated by High- Energy electron beam irradiation, Mater.sci.Eng A.2002,233. P 201-259

[2] P.Persson, AEW. Jarfons, and S.Savage, selfpropagation High temperature synthesis and liquid phase sintering of TiC/Fe composites J, Mater Technol, 2002, 127 P 131-139.

[3] Hego Zhu, Kang Dong, Huan Wang, Reaction mechanisms of $\mathrm{TiC} / \mathrm{Fe}$ composites fabricated by exothermic dispersion from Fe-Ti-C element system, Powder Technology 246[2013] 456-561 Elsevier.

[4] R.M German, Liquid Phase sintering, Plenum press, NewYark, 1995.

[5] T.K Bandyopadyay, K. Das, Synthesis and characterisation of TiC-Reinforced iron-based composites part-II on mechanical characterisation. Journal of material science 39 [2004] 6503-6508. 
[6] E Pagoumi's and V.K lindoors, processing and properties of particulate reinforced steel matrix composites, Mat, Sci and eng.A. 246[1998].P 221.

[7] H Reshetnyk and J kubarsepp, structure sensitivity of wear resistance of hard metals.Int.J. Ref. Mat, 15[1997].P.89.

[8] K.I. Parashivamurthy, $P$ Sampath kumar and S.Seetharam. In-situ precipitation in molten $\mathrm{Fe}-\mathrm{C}$ and their characterisation. Cryst, Res Technology, 43, No.6, 674-678[2008]

[9] P. Ehrenfest, Proe, Acid, sci. Amsterdam 36,153[1933].

[10] K.I Parashivamurthy R.K.Kumar S.Seetharamu and M.N.Chandrashekaraiah. J. Material sci. 36, 4519[2001].

[11] Qihong Cen, Yehua Jiang, Rong Zhou, YunhuaXu, Jianibin Wang, Study on In situ Synthesis of Tic particle Reinforced Iron Matrix Composite, ASM International, JMEPEG(2011), vol 20, 1447-1450.

[12] Terry, B.S., B.S. Chinyamakobvu, O. Dispersion and Reaction of $\mathrm{TiC}$ in liquid iron alloys.Mater. Sci. Technol.1992, 8,399-405.

[13] Wang Jing, Wang Yisan, In-situ Production of Fe-TiC Composite, Elsevier, Material letters, 61(2007) 43934395.

[14] Ray. S. Review synthesis of cast metal matrix particulate metal matrix composites J.Mat.Sci.1993, 28, 5397-5413.

[15] Hego Zhu, Kang Dong, Huan Wang, Reaction mechanisms of $\mathrm{TiC} / \mathrm{Fe}$ composite fabricated by exothermic dispersion from Fe-Ti-C element system, Powder Technology 246(2013) 456-461, Elsevier.

[16] K.I. Parashivamurthy, M.N. Chandrashekaraiah.P Sampath kumar and S.Seetharam. Casting of TiCReinforced steel matrix composite. Materials and manufacturing processes, 21; 473-478, 2006 